\title{
Factors Associated with Acquired Infections Caesarian Wounds in Maternity Mbuji-Mayi/DR Congo
}

\author{
Jean Christophe Bukasa1*, Augustin Kadiata1, Andre Guillaume Kabongo', Didier Lepelletier², \\ Decas Blood Banzaㄹ, Jean Jacques Bukasa1, Félicien Ilunga ${ }^{3}$, Andre Mutombo4, \\ Senghor Ngoyi Mbo5, Angelique Bandimuna5, Sébatien Kashimpo5, Alexis Ntambwe6, \\ Stany Wembonyama ${ }^{7}$
}

\footnotetext{
${ }^{1}$ Higher Institute of Medical Techniques of Mbuji-Mayi, Mbuji-Mayi, Democratic Republic of the Congo

${ }^{2}$ Emerging Laboratory MiHAR, Faculty of Medicine, University of Nantes, Nantes, France

${ }^{3}$ Higher Institute of Medical Technologies of Kinshasa, Kinshasa, Democratic Republic of the Congo

${ }^{4}$ Official University of Mbuji-Mayi, Mbuji-Mayi, Democratic Republic of the Congo

${ }^{5}$ Higher Institute of Medical Technologies of Kabinda, Kabinda, Democratic Republic of the Congo

${ }^{6}$ Higher Institute of Medical Technologies of Lubao, Lubao, Democratic Republic of the Congo

${ }^{7}$ School of Public Health, University of Lubumbashi, Lubumbashi, Democratic Republic of the Congo

Email: *jcbukasa4@gmail.com
}

How to cite this paper: Bukasa, J.C., Kadiata, A., Kabongo, A.G., Lepelletier, D., Banza, D.B., Bukasa, J.J., Ilunga, F., Mutombo, A., Mbo, S.N., Bandimuna, A., Kashimpo, S., Ntambwe, A. and Wembonyama, S. (2018) Factors Associated with Acquired Infections Caesarian Wounds in Maternity Mbuji-Mayi/ DR Congo. Open Access Library Journal, 5: e4437.

https://doi.org/10.4236/oalib.1104437

Received: February 22, 2018

Accepted: March 26, 2018

Published: March 29, 2018

Copyright $\odot 2018$ by authors and Open Access Library Inc.

This work is licensed under the Creative Commons Attribution International License (CC BY 4.0).

http://creativecommons.org/licenses/by/4.0/

(c) (†) Open Access

\begin{abstract}
Introduction: The purpose of this study is to analyze the factors associated with nosocomial infections of caesarean section wounds in the maternity hospitals of the city of Mbuji-Mayi. Methods. This study was conducted in 25 maternities of general referral hospitals, clinics and hospitals in the city of Mbuji-Mayi during the period from 1 February to 1 June 2017, out of 171 parturients cesarized that were followed during a period of 4 months. A survey questionnaire was used to collect the data. Results. Out of 171 parturients monitored, surgical site infection developed 52 (SSI), an incidence of $30.4 \%$. After analysis, nine factors were identified as associated post-caesarean SSI in Mbuji-Mayi city $(\mathrm{p} \leq 0.05)$ : age $(\mathrm{p}=0.000)$, anemia $(\mathrm{p}=0.000)$, prolonged duration of labor delivery $(p=0.001)$, premature rupture of the membranes before caesarean section $(\mathrm{p}=0.044)$, prolonged duration after-rupture of the membranes $(\mathrm{p}=0.000)$, preparation of the operative site by shaving $(\mathrm{p}=$ $0.029)$, surgery by general practitioner $(p=0.023)$, duration of operation greater than 60 minutes $(\mathrm{p}=0.040)$, non-compliance with asepsis during dressing $(\mathrm{p}=0.000)$. Conclusion: The fight against nosocomial infections must be a permanent concern: the prevention and regular monitoring of these infections must be the control strategies of each hospital structure, under the watchful eye of a coordination center for the fight nosocomial infections.
\end{abstract}




\section{Subject Areas}

Epidemiology

\section{Keywords}

Factors, Nosocomial Infections, Caesarean Section Wounds

\section{Introduction}

Despite the enormous progress made in obstetric technique and anesthesia to provide better maternal-fetal safety during cesarean section, the rates of maternal complications and surgical site infections remain high, putting some time in life-threatening and obstetric outcome of patients [1]. The operating site nosocomial infections are the second cause of premature death and the third leading cause of neo-maternal mortality [2].

It is estimated that 18.5 millions sections are made in the world each year and that the incidence of surgical site infections after surgery is $5 \%$ to $11.2 \%$. In developed countries the total SSI after cesarean ranges from $1.5 \%$ to $7 \%$; the incidence of superficial infections is estimated at approximately $0.18 \%$, endometritis $3 \%-6 \%$; by cons in developing countries the impact of SSI varies from approximately $6 \%$ to $15 \%[3]$.

In Asia, specifically in New Delhi (India), the coincidence of surgical site infections after cesarean is higher because a study in the Obstetrics and Gynecology Department of Lady Hardinge Medical College. And the Suchete Kriplani Hospital reports a rate of $24.2 \%$ or 121 women out of 500 [4] [5] [6]. In some European countries it is reported a rate of $8.3 \%$ in Norway in 2009 and $8.9 \%$ in England in 2008 [7]. In Africa the incidence of nosocomial infections caesarean wounds ranges from $9,1 \%$ to $22.3 \%$ [8] [9], with a lethality of $2.9 \%$ [10] [11].

In most cases, these infections affect women of low socioeconomic class [12] and women of young age (21 - 25 years) [5]; and they are more common in maternity hospitals in rural and urban [3].

The surgical site infections in post cesarean are serious complications that can lead to further surgery, increased medical costs and long hospital stay, re-hospitalization, prolongation of maternal functioning back and mortality [10] [13].

To reduce these infections, it is necessary to install surveillance programs for nosocomial infections, [14]. In addition antibiotic prophylaxis reduces the incidence of wound infections after cesarean section, endometritis and other serious complications in $60 \%-70 \%$ of cases [15] [16] [17].

The objective of this study was to analyze factors associated with nosocomial infections caesarean wounds in maternity structures of the city of Mbuji-Mayi.

\section{Methods}

It is a study conducted in 25 maternity wards of general hospitals references, 
clinics and hospitals of the city of Mbuji-Mayi, during the period from 1 February to 1 June 2017. In total, the sample consisted of 171 women in labor caesareans who were followed over a 4 month period. It is the sample exhaustive obtained on the basis of the following selection criteria for inclusion:

- Having had a caesarean section in one of the structures concerned;

- To be hospitalized during the period of our investigation;

- Agree to participate voluntarily in the study.

For exclusion criteria, all caesarized parturients who did not meet the inclusion criteria were excluded from the study.

Data collected by questionnaire were encoded using the EXCEL 2007 and analyzed by the EPI-INFO Version 3.5.3 software, using the chi-square test to analyze the association relationships between variables independent and dependent variable. The following variables were considered in this study:

a) Dependent variable: nosocomial infection of caesarean section wounds.

b) Independent variables

1) Sociodemographic characteristics:

- Age

- Parity

- Marital status

- Level of study

- Previous pathologies: anemia, diabetes, HIV, obesity, high blood pressure, nutritional status

2) Factors related to child labor:

- Duration of labor

- Membrane status

- Number of vaginal touch intra uterine monitoring

3) Factors related to the intervention:

- Type of Anesthesia

- Caesarean section

- Number of cesarean section

- Nature of the intervention room

- Type of incision

- Number of people in the operating room

- Qualification of the surgeon

- Duration of the operation

- Nature of the preparation of the operation site (shaving or removal) antibiotic

4) Environmental factors:

- Preoperative hospitalization

- Respect for the hygiene of the sick ward

- Length of hospital stay in post operation

- Hand hygiene

- Hygiene of the hospital room 
5) Factors related to postoperative care

Type of dressing; respect of asepsis during the dressing; quality of the equipment used.

\section{Ethical Considerations}

This study had been approved by the Interuniversity Ethics Committee of the city of Mbuji-Mayi. Then free and informed consent was obtained in writing for any caesarized woman who participated in the study.

\section{Results}

\subsection{Results Descriptive Analyses}

Figure 1 shows that the incidence of cesarean wounds infection is $30.6 \%$.

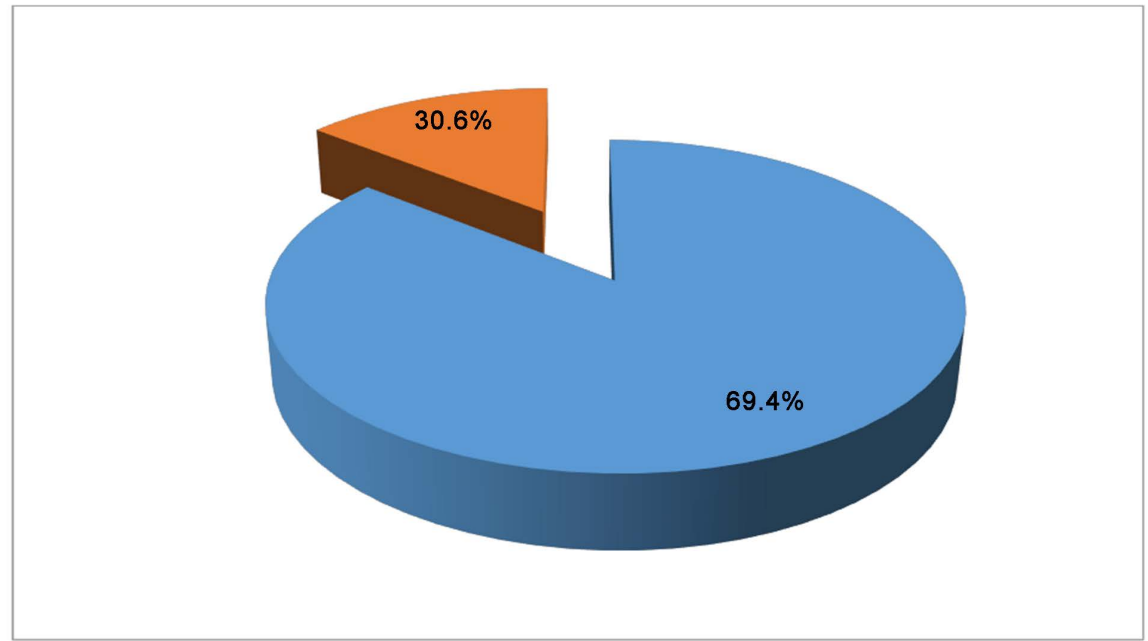

Figure 1. Show that the incidence of cesarean wounds infection is $30.6 \%$.

Figure 2 shows that deep infection of cesarean wounds is $5.2 \%$.

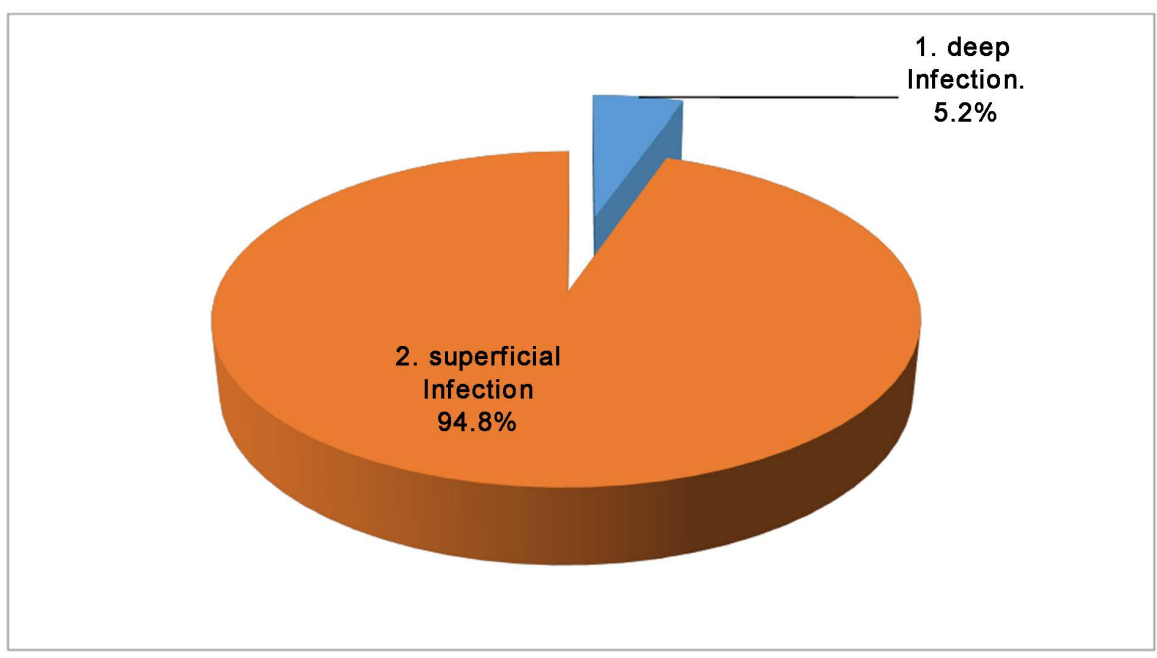

Figure 2. Show that deep infection of cesarean wounds is $5.2 \%$. 
Table 1 shows that the age of parturients aged 20 and over is represented, or $87.1 \%$, against that of $\leq 19$ years with $12.9 \%$ and overall average age was $29.9 \pm$ 40 years. Parturient with $\leq 5$ parity represent $66.7 \%$ and those with parity of 6 or more $33.3 \%$. Generally, women in labor did not present obesity, that in view of the BMI shows that $83.0 \%$ have a clue $\leq 29$. The majority of women in labor are married $91.8 \%$, most of them have not finished the study of junior high, $66.7 \%$ against $33.3 \%$ of those graduates and more.

Table 1. Distribution of caesareans according sociodemographic characteristics.

\begin{tabular}{cccc}
\hline Feature & Category & Effective $\mathbf{n}=\mathbf{1 7 1}$ & $\%$ \\
\hline Age (year) & $\leq 19$ & 22 & 12.9 \\
& 20 and more & 149 & 87.1 \\
Average age & $29.9 \pm 40$ & & \\
Parity & $\leq 5$ & 114 & 66.7 \\
& 6 and more & 57 & 33.3 \\
Body mass index (BMI) & $\leq 29$ & 142 & 83.0 \\
& & 29 & 17.0 \\
marital status & married & 157 & 91.8 \\
Study level & single & 14 & 8.2 \\
& not graduate D6 & 114 & 66.7 \\
& Graduate or more & 57 & 33.3 \\
\hline
\end{tabular}

Table 2 shows that surveyed caesarean parturient are less affected by hypertension and/or preeclampsia (20.5\%), diabetes (2.9\%), the HIV infection (0.6\%), or malnutrition (2.9\%); except $69.0 \%$ against $31.0 \%$ who presented anemia.

Table 2. Distribution of caesareans as underlying diseases.

\begin{tabular}{cccc}
\hline Pathology & Category & Effective $\mathbf{n}=\mathbf{1 7 1}$ & \% \\
\hline \multirow{2}{*}{ Anemia } & Yes & 53 & 31.0 \\
& No & 118 & 69.0 \\
Hypertension/preeclampsia & Yes & 35 & 20.5 \\
& No & 136 & 79.5 \\
Diabetes & Yes & 5 & 2.9 \\
& No & 166 & 97.1 \\
HIV & Yes & 1 & 0.6 \\
& No & 170 & 99.4 \\
Malnutrition & Yes & 1 & 0.6 \\
& No & 170 & 99.4 \\
\hline
\end{tabular}

Table 3 shows that general anesthesia is used in many cases caesarean section is $84.8 \%$ of cases, the incision types commonly used are vertical incision (70.8\%) and the transverse incision (29.2\%). Many cases are brought in emer- 
gency cesarean is $90.1 \%$, and most of the caesarean or $81.9 \%$ were operated for the first time; surgery was done in an operating room for 170 cases or $99.4 \%$. The preparation of the operative site was made $98.8 \%$. The number of people who attended the operation in the majority of interventions did not exceed 5 people $(64.3 \%)$, and $35.7 \%$ for 6 or more. More C-sections were performed by general practitioners $(61.4 \%)$. The duration of the operation has not exceeded 60 minutes in $35.1 \%$ of cases and more than 60 minutes in $64.9 \%$. Antibiotic prophylaxis was made in $92.4 \%$.

Table 3. Distribution of surgical characteristics according cesarized.

\begin{tabular}{|c|c|c|c|}
\hline Feature & Category & Effective $n=171$ & $\%$ \\
\hline \multirow{2}{*}{ Type of anesthesia } & regional & 26 & 15.2 \\
\hline & general & 145 & 84.8 \\
\hline \multirow{2}{*}{ Type of incision } & Vertical & 121 & 70.8 \\
\hline & transversal & 50 & 29.2 \\
\hline \multirow{2}{*}{ Fashion caesarean } & programmed & 17 & 9.9 \\
\hline & Emergency & 154 & 90.1 \\
\hline \multirow{2}{*}{ Number of caesarean } & 1 time & 140 & 81.9 \\
\hline & 2 and more & 31 & 18.1 \\
\hline \multirow{2}{*}{ Operation middle } & operating room & 170 & 99.4 \\
\hline & Delivery room & 1 & 0.6 \\
\hline \multirow{2}{*}{$\begin{array}{l}\text { Preparation of the } \\
\text { operation site }\end{array}$} & by depilation & 2 & 1.2 \\
\hline & by shaving & 169 & 98.8 \\
\hline \multirow[t]{2}{*}{$\begin{array}{l}\text { Number of people in the } \\
\text { operating room }\end{array}$} & $\leq 5$ & 110 & 64.3 \\
\hline & 6 and more & 61 & 35.7 \\
\hline \multirow{2}{*}{ Surgeon Qualifications } & general practitioner & 105 & 61.4 \\
\hline & Specialist & 66 & 38.6 \\
\hline \multirow{2}{*}{ Duration of the operation } & $\leq 60$ minutes & 60 & 35.1 \\
\hline & 61 minutes and more & 111 & 64.9 \\
\hline \multirow[t]{2}{*}{ Antibiotic } & Yes & 158 & 92.4 \\
\hline & no & 13 & 7.6 \\
\hline
\end{tabular}

In Table 4, the majority of women in labor caesareans have been hospitalized prior to the cesarean is $93.0 \%$, against a $7.0 \%$ of cases were hospitalized before undergoing the operation. During the post-operation hospital, there are many cesarized spent a stay of 15 days or more (81.9\%). $63.2 \%$ of caesareans perform regular washing of hands, against $36.8 \%$ of cases that are not running the practice. By cons, only $24.0 \%$ of patients guards perform this practice, against $76.0 \%$ who did not run. The hospital room caesarean was cleaned regularly every day in 98.9\%. 
Table 4. Distribution of caesareans in connection with the living and hygiene of the hospital environment.

\begin{tabular}{cccc}
\hline Stay and hyg. of approx. Hosp & Category & Effective & \% \\
\cline { 3 - 4 } Hospitalization prior cesarean & Yes & 12 & 7.0 \\
$\begin{array}{c}\text { Number of days post operation } \\
\text { hospitalization }\end{array}$ & No & 159 & 93.0 \\
$\begin{array}{c}\text { Regular hand washing by } \\
\text { cesarized }\end{array}$ & Yes & 31 & 18.1 \\
Regular hand washing in the & No & 140 & 81.9 \\
custody of the cesarized & Yes & 108 & 63.2 \\
& No & 63 & 36.8 \\
Cleaning the hospital room & Yes & 130 & 24.0 \\
& No & 152 & 76.0 \\
\hline
\end{tabular}

In Table 5, the dressing benefited by caesarean postoperative antiseptic is dry type in $73.1 \%$ of cases and $26.9 \%$ for the other types (antiseptic to dry or wet dakin). The aseptic dressing was observed during $33.3 \%$, against $66.7 \%$ of non-compliance. The quality of material used for the dressing was generally sterile in $83.6 \%$ of cases.

Table 5. Distribution of caesareans as postoperative care received.

\begin{tabular}{cccc}
\hline Post-operative care & Category & Effective $\mathbf{n}=171$ & $\%$ \\
\hline Type dressing & $\begin{array}{c}\text { antiseptic Dry iodinated } \\
\text { alcohol/polividone } \\
\text { other types }\end{array}$ & 152 & 88.9 \\
$\begin{array}{c}\text { Respect for the aseptic } \\
\text { dressing }\end{array}$ & Yes & 19 & 11.1 \\
$\begin{array}{c}\text { Quality of the material used } \\
\text { for the dressing }\end{array}$ & No & 57 & 33.3 \\
& Steril unsterile & 114 & 66.7 \\
& unsterile & 143 & 83.6 \\
\hline
\end{tabular}

\subsection{Results of the Bi-Varied Analysis}

In this Table 6, the difference between the sociodemographic characteristics and the occurrence of cesarean wound infection is significant only for age $(\mathrm{p}=$ 0.000).

In Table 7, among the underlying pathologies observed in caesarean, anemia showed a significant difference $(\mathrm{p}=0.000)$.

In Table 8, the duration of the delivery work, the rupture of membranes before cesarean section and length after rupture of the membranes showed a sig- 
nificant difference, because the value of the $\mathrm{p}$ value is less than 0.05 (respectively $\mathrm{p}$ value of $0.001 ; 0.0443$ and 0.000 ).

Table 6. Association between socio-demographic characteristics and the occurrence of infection of cesarean wound.

\begin{tabular}{|c|c|c|c|c|c|}
\hline \multirow{3}{*}{$\begin{array}{c}\text { Sociodemographic } \\
\text { characteristic }\end{array}$} & \multicolumn{2}{|c|}{ Infection } & \multirow{3}{*}{$\mathrm{X} 2$} & \multirow{3}{*}{$\mathrm{p}$} & \multirow{3}{*}{ Meaning } \\
\hline & Yes & No & & & \\
\hline & $\mathrm{n}=52$ & $\mathrm{n}=119$ & & & \\
\hline \multicolumn{6}{|l|}{ Age } \\
\hline$\leq 19$ years & 14 & 8 & 13.172 & 0 & S \\
\hline 20 years and over & 38 & 111 & & & \\
\hline \multicolumn{6}{|l|}{ Parity } \\
\hline$\leq 5$ childbirth & 32 & 82 & 0.884 & 0.347 & NS \\
\hline$\geq 6$ childbirth & 20 & 37 & & & \\
\hline \multicolumn{6}{|l|}{ BMI } \\
\hline$\leq 29$ & 47 & 95 & 0.568 & 0.478 & NS \\
\hline$\geq 30$ & 5 & 24 & & & \\
\hline \multicolumn{6}{|l|}{ Marital status } \\
\hline Not married & 50 & 107 & 1.8732 & 0.171 & NS \\
\hline Married & 2 & 12 & & & \\
\hline \multicolumn{6}{|l|}{ Study level } \\
\hline not graduated & 37 & 77 & 0.6770 & 0.41 & NS \\
\hline
\end{tabular}

Table 7. Association between the underlying pathologies in caesarean and the occurrence of wound infection.

\begin{tabular}{|c|c|c|c|c|c|}
\hline \multirow{2}{*}{ underlying diseases } & \multicolumn{2}{|c|}{ Infection } & \multirow{2}{*}{$\mathrm{X} 2$} & \multirow{2}{*}{$\mathrm{p}$} & \multirow{2}{*}{ meaning } \\
\hline & Yes $n=52$ & No $n=119$ & & & \\
\hline \multicolumn{6}{|l|}{ Anemia } \\
\hline Yes & 28 & 25 & 18.2446 & 0 & S \\
\hline no & 24 & 94 & & & \\
\hline \multicolumn{6}{|c|}{ Hypertension/preeclampsia } \\
\hline Yes & 6 & 29 & 3.6600 & 0.055 & NS \\
\hline no & 46 & 90 & & & \\
\hline \multicolumn{6}{|l|}{ Malnutrition } \\
\hline Yes & 1 & 4 & 0.263 & 0.607 & NS \\
\hline no & 51 & 115 & & & \\
\hline \multicolumn{6}{|l|}{ HIV } \\
\hline Yes & 1 & 2 & 0.345 & 0.712 & NS \\
\hline No & 49 & 119 & & & \\
\hline
\end{tabular}


Table 8. Association characteristics of childbirth labor and infection of cesarean wound.

\begin{tabular}{|c|c|c|c|c|c|}
\hline \multirow{2}{*}{ Features into labor } & \multicolumn{2}{|c|}{ Infection } & \multirow{2}{*}{$\mathrm{X} 2$} & \multirow{2}{*}{$\mathrm{p}$} & \multirow{2}{*}{ Meaning } \\
\hline & Yes $n=52$ & No $n=119$ & & & \\
\hline \multicolumn{6}{|l|}{$\begin{array}{c}\text { Labor before } \\
\text { cesarean Presence }\end{array}$} \\
\hline \multicolumn{6}{|l|}{ Yes } \\
\hline \multirow[t]{2}{*}{ No } & 50 & 103 & 0.3109 & 0.577 & NS \\
\hline & 2 & 16 & & & \\
\hline \multicolumn{6}{|l|}{$\begin{array}{l}\text { Working hours before } \\
\text { caesarean }\end{array}$} \\
\hline \multicolumn{6}{|l|}{$\leq 10$ hours } \\
\hline \multirow[t]{2}{*}{10 hours and more } & 15 & 49 & 9.8575 & 0.001 & S \\
\hline & 35 & 70 & & & \\
\hline \multicolumn{6}{|c|}{$\begin{array}{c}\text { Number of vaginal affected } \\
\text { before caesarean }\end{array}$} \\
\hline \multicolumn{6}{|l|}{$\leq 3$ times } \\
\hline \multirow[t]{2}{*}{4 times more } & 20 & 50 & 0.009 & 0.924 & NS \\
\hline & 32 & 69 & & & \\
\hline \multicolumn{6}{|l|}{$\begin{array}{l}\text { Status of the membrane } \\
\text { before cesarean }\end{array}$} \\
\hline \multicolumn{6}{|l|}{ intact } \\
\hline \multirow[t]{2}{*}{ broken } & 33 & 64 & 4.041 & 0.0443 & S \\
\hline & 19 & 55 & & & \\
\hline \multicolumn{6}{|l|}{$\begin{array}{l}\text { Number of hours of } \\
\text { breaking the caesarean }\end{array}$} \\
\hline \multicolumn{6}{|l|}{$\leq 10$ Hours } \\
\hline \multirow[t]{2}{*}{10 hours and more } & 5 & 0 & 22.510 & 0 & S \\
\hline & 14 & 55 & & & \\
\hline
\end{tabular}

In Table 9, there is a significant difference between the way of preparing the surgical site $(p=0.029)$, the qualification of the surgeon $(p=0.023)$, the duration of the operation $(\mathrm{p}=0.040)$ and the occurrence of wound infection because the $\mathrm{p}$ value is less than 0.05 .

Table 9. Association surgical characteristics and the occurrence of wound infection.

\begin{tabular}{ccccccc}
\hline \multirow{2}{*}{ Surgical Features } & \multicolumn{2}{c}{ Infection } & X2 & p & Meaning \\
\cline { 2 - 4 } & Yes $\mathbf{n}=\mathbf{5 2}$ & No $\mathbf{n}=\mathbf{1 1 9}$ & & & \\
\hline Type of anesthesia & 8 & 18 & 0.102 & 0.748 & NS \\
\hline Regional & 44 & 101 & & & \\
General & & & & & \\
\hline Type of incision & 34 & 87 & 0.722 & 0.395 & NS \\
\hline Vertical & & & & & \\
\hline
\end{tabular}




\section{Continued}

\begin{tabular}{|c|c|c|c|c|c|}
\hline Transverse & 18 & 32 & & & \\
\hline \multicolumn{6}{|l|}{ Fashion caesarean } \\
\hline Program & 4 & 13 & 0.411 & 0.521 & NS \\
\hline Emergency & 48 & 106 & & & \\
\hline \multicolumn{6}{|l|}{$\begin{array}{l}\text { Number of previous } \\
\text { cesareans }\end{array}$} \\
\hline 1 time & 6 & 25 & 2.186 & 0.139 & NS \\
\hline 2 fois more & 46 & 94 & & & \\
\hline \multicolumn{6}{|l|}{ Place of intervention } \\
\hline operating room & 49 & 119 & 2.347 & 0.125 & NS \\
\hline Delivery room & 1 & 2 & & & \\
\hline \multicolumn{6}{|l|}{$\begin{array}{c}\text { Preparation of the } \\
\text { operation site }\end{array}$} \\
\hline by depilation & 2 & 1 & 4.722 & 0.029 & S \\
\hline by shaving & 48 & 119 & & & \\
\hline \multicolumn{6}{|l|}{$\begin{array}{c}\text { Number of people in the } \\
\text { operating room }\end{array}$} \\
\hline \multicolumn{6}{|l|}{$\leq 5$} \\
\hline \multirow[t]{2}{*}{6 and more } & 37 & 73 & 2.327 & 0.312 & NS \\
\hline & 15 & 46 & & & \\
\hline \multicolumn{6}{|l|}{ Surgeon qualifications } \\
\hline general practitioner & 28 & 77 & 5.151 & 0.023 & S \\
\hline Specialist & 24 & 42 & & & \\
\hline
\end{tabular}

\section{Discussion}

\subsection{Results of the Descriptive Analysis}

\subsubsection{In Relation to Sociodemographic Characteristics}

The age group of 20 and older was most represented with $87.1 \%$. The mean age was $29.9 \pm 40$ years. Women with parity $\leq 5$ deliveries accounted for $66.7 \%$. The majority of women were married (91.8\%); and most of them were less educated (66.7\%), which may not justify the mastery of hospital hygiene measures and increasing the frequency of nosocomial infections. In the study conducted in Nairobi by Kabua M. (2013), on a sample of 184 women, average age was very close to that of our study, $27.4 \pm 5.62$ years with a range of 16 - 46 years [9].

\subsubsection{In Connection with Existing Pathologies in Caesareans}

Caesarean women surveyed are less affected by hypertension and/or preeclampsia $(20.5 \%)$, diabetes $(2.9 \%)$, the HIV infection $(0.6 \%)$, or malnutrition $(2,9 \%)$; except that $69.0 \%$ presented anemia. As against Oman in a study conducted at the HANSA reference regional hospital D. et al. [18], the results found show that diabetes, anemia, hypertension and eclampsia, obesity were frequently found 
among cesarized [13].

\subsubsection{In Connection with Childbirth Labor Characteristics}

Ninety-nine point four percent of women were into labor before cesarean section; $58.2 \%$ of cesarized had a prolonged labor (10 hours or more) before cesarean section, $59.1 \%$, are the number of vaginal examinations performed prior cesarean section at a frequency of 4 times or more. Most women made cesarean section with membranes ruptured for 10 hours or more (93.2\%.). Or, the longer the delivery time is prolonged, the number of vaginal examinations increase and in addition there is premature rupture of membranes, the easier the penetration of germs into the uterine cavity. This met the study in India by GONG SP et al. where the premature rupture of membranes was common in $83.7 \%$ of cases, prolonged duration of the operation, the excessive number of vaginal examination during hospitalization was $75.2 \%$ of the cases [19].

\subsubsection{In Connection with Surgical Characteristics}

General anesthesia was used in $84.8 \%$ of cases; the type most commonly made of incision is the vertical incision (70.8\%); many of cesarean cases are brought in emergency in $90.1 \%$ of cases, and most cesarean $(81.9 \%)$ were operated for the first time; the preparation of the surgical site was made in $98.8 \%$ of cases. Caesarean sections performed by GPs totaled $61.4 \%$ of cases; the duration of the operation exceeded more than 60 minutes in $64.9 \%$. This appears to be hampered by the fact in China where prolonged operation time is $81.7 \%$ of cases), and the non-antibiotic in $75.2 \%$ of cases [19].

\subsubsection{The Characteristics of the Hospital Environment and Hospital Hygiene}

During the post-operation room, many of caesarean section (81.9\%) spent a long stay (15 days or more), this is explained by the presence of wound infection which delays healing and prolongs hospital stay; but also justified by the lack of financial resources to meet the requirements of the exit to the hospital.

\subsubsection{In Connection with the Post-Operative Care Received}

The dressing benefited by caesarean postoperative antiseptic is dry type for $73.1 \%$ and $26.9 \%$ for the other types (antiseptic to dry or wet dakin) but asepsis during dressing is respected that $33.3 \%$. This weakness typically falls under the negligence of health workers during the implementation of care and also by the lack of sufficient material to administer the required quality care.

\subsubsection{In Connection with the Categories of Infected Wounds Cesarean} Ninety four point two percent of infected Caesarean section wounds are superficial, while only $5.8 \%$ are profound. These results confirm those found in the study conducted in India in New Delhi, where $96.2 \%$ of the infections were superficial and deep infections 3.7\% [12]. By cons a study in Thailand proves otherwise, where about 293 who developed ISO, 10.9\% of infections were superficial, $6.2 \%$ and $82.9 \%$ deep infections organ infections [1]. 


\subsection{Results of the Bi-Variegated Analysis}

In this study, wanting to verify the association of sociodemographic characteristics and the occurrence of wound infection, age showed a significant association $(p<005)$. For the association between existing pathologies in cesarized and the occurrence of wound infection, anemia showed a significant association ( $\mathrm{p}<$ 0000).

In the association of the characteristics of childbirth labor and infection of the cesarean wound, the duration of delivery of the work and the time after rupture of the membranes shows a statistically significant difference $(\mathrm{p}<0.05)$. So more working time is extended, the more the time of rupture of membranes is long, the greater the risk of rise of the vagina to the uterus germs, the more cesarized is likely to develop an infection of the wound. In addition there is a significant difference between the way of preparing the surgical site $(p=0.029)$, the qualification of the surgeon $(\mathrm{p}=0.023)$, the duration of the operation $(\mathrm{p}=0.040)$ and the occurrence of infection the wound. Over the surgical site is prepared by shaving, the longer the duration of the intervention is long (over 60 minutes) and more surgery is made by a non-specialist, the higher the risk of infection is high. In England, a study done at the hospital, fourteen of the frequency and the ISO risk factors, shows a contradiction in relation to age, but confirmed the qualification of doctor as associated factor [20]. Thus the major factors associated with surgical site infection are obesity (BMI greater than 35; OR 3.7, 95\% CI 2.6 to 5.2 ); the young age of women (under 20 years. OR 1.9; 95\% CI 1.1 to 3.4 ), so that the intervention by a young GP (OR 1.6; $95 \%$ CI 1.0 to 2.4 ) also act as factors influencing [20].

But this study supports the results of several studies conducted around the world, for illustrative purposes we include the study conducted in Tanzania which falls six preachers factors of infection: high blood pressure during pregnancy (OR 2.5, $951.1 \%$ to 5.6\%; p = 0.021), severe anemia (OR 3.8; 95\% CI 1.2 to $12.24 ; \mathrm{p}=0.028)$, repeated vaginal examination (OR $2.5,95 \% 1,5$ to $5.1 ; \mathrm{p}=$ 0.011 ), prolonged operation time (OR 2.6; $95 \%$ CI 1.2 to $5.5 ; \mathrm{p}=0.015$ ) and the operation performed by a young non-specialist physician (OR 4, 0, 95\% CI 1.7 to $9.2 ; \mathrm{p}=0.001)[10]$.

In addition, there is a significant difference between respect for the aseptic dressing and infection of cesarean wound $(p<0.05)$. So when we do not respect the aseptic dressing for a wound, you run a high risk of infection from it. This is an unprivileged appearance in several studies on the factors associated with infection post cesarean section surgical site.

\section{Conclusions}

The incidence of nosocomial infections of caesarean wounds in 25 hospitals that have covered our study in the city of Mbuji-Mayi amounts to $30.4 \%$ for a period of 4 months.

The fight against nosocomial infections must be a permanent concern; pre- 
vention and regular monitoring of these infections should be the fight of every hospital structure strategies. In addition, the staff must ensure that aseptic procedures are performed in all surgical procedures, specifically cesareans, bath chlorhexidine gluconate the night before surgery, if necessary mow the pubic hair rather than shave, avoid unnecessary iterative vaginal examinations during labor, avoid necessarily using the instruments vaginally during labor, administration of antibiotic prophylaxis 60 minutes before the incision, prepare the skin with an antiseptic immediately before the operation, avoid manual separation of the placenta and fetal membranes [21].

\section{References}

[1] Assawapalanggool, S., Kasatpibal, N., Sirichotiyakul, S., Arora, R. and Suntornlimsiri, W. (2016) Risk Factors for Cesarean Surgical Website Infections at Thai-Myanmar Border Hospital. American Journal of Infection Control, 44, 990-995. https://doi.org/10.1016/j.ajic.2016.01.031

[2] Biltery, R. and Milord, F. (2008) Prevention of Nosocomial Infections, Also a Hot Topic in Developing Countries. Perceptive Nurse, 3, 20-26.

[3] Borq, T.F., Ali, K.K., Salahaldeem, A.S. and Alkallaf, A.S. (2016) Impact and Risk Factors for Surgical Site Infection Following Cesarean Section in a Tertiary Care University Hospital. Journal of Evidence-Based Women's Health, 6, 51-57. https://doi.org/10.1097/01.EBX.0000481362.51250.6c

[4] Chu, K., Maine, R. and Trelles, M. (2015) Cesarean Section Surgical Infection Site in Sub-Saharan Africa: A Multi Country Study from Doctors without Frontiers. World Journal of Surgery, 39, 350-355. https://doi.org/10.1007/s00268-014-2840-4

[5] De, D., Saxena, S., Mehta, G., Yadav, R. and Dutta, R. (2013) Risk Factor Analysis and Microbial Etiologies' of Surgical Infection Site Following Lower Segment Caesarean Section. International Journal of Antibiotics, 2013, Article ID: 283025, 6 p.

[6] Dupont, J., Ngowa, K., Ngassam, A., Tsuala Fouogue, J., Metogo, J., Medou, A. and Kasia, J.M. (2015) Early Complications of Cesarean Section: About 460 of These in Teaching Hospitals of Yaounde. Pan African Medical Journal, 21. http://www.panfarican-med-journal.com/article/21/165/fu

[7] Césarine, L. (2016) The Consequences of Caesarean Section for the Mother: Risk of Surgical Site Infection. The Journal Obstetrics and Gynecology Research, 38, 509-515.

[8] Jido, T.A. and Garba, I.D. (2012) Surgical Site Infection Following Cesarean Section in Kano. Annals of the Medical and Health Sciences Research, 2, 33-36. https://doi.org/10.4103/2141-9248.96934

[9] Kabua, M. (2014) Incidence Year Determinants of Surgical Infection After-Site Caerean Delivery at Kenya National Hospital. Dissertation, University of Nairobi, Nairobi.

[10] Mpogoro, F.J., Mshama, S.E., Mirambo, M.M., Kindenya, B.R., Gumodoka, B. and Imizalioglu, C. (2014) Incidence and Predictors of Surgical Site Infection Following Caesarean Section at Bugando Medical Center, Mwanza, Tanzania. Antimicrobial Resistance \& Infection Control, 3, 25.

[11] Opoien, H.K., Valbo, A., Grinde-Andersen, A. and Walberg, M. (2007) Post-Cesarean Surgical Website Infections to CDC Occording Standars: Rates and Risk Factors. Acta Obstetricia et Gynecologica Scandinavica, 86, 1097-1102. 
[12] Dahiya, P., Gupta, V., Prindir, S. and Chawla, D. (2016) Study of Impact and After-Risck Factors for Surgical Cesarean at First Referral UNIT. International Journal of Contemporary Medical Research, 3, 1102-1104.

[13] Cunningham, F.G. (2002) Post Operative Complication in Operative Obstetrics. 2nd Edition, McGraw Hill, New York, 293-309.

[14] Vincent, A. (2014) Nosocomial Infections in Women Delivered by Caesarean Section. http://cclinsudest.chulyon.fr/Reseaux/MATER/Journee/2014/CR_14

[15] Malik, A.Z. and Ali, Q. (2014) Surgical Site Infections after Elective Surgery. Journal of Rawalpindi Medical College, 19, 209-214.

[16] 18Dhar, H., Al-Busaidi, I., Rathi, B., Nimre, E.A., Sachdeva, V. and Hamdi, I. (2014) A Study of Post-Caesarean Section Wound Infections in a Regional Referral Hospital Oman. Sultan Qaboos University Medical Journal, 14, e211-e217.

[17] Smail, F.M. and Mgrivel, R. (2014) Antibitic Prophylaxis versus No Prophylaxis for Infection Preventing After-Cesearen Section. Cochrane Data Base of Systemic Reviews, No. 10, CD007482. http://www.cochranelibrary.com

[18] Tita, A.T., Stam, O.J., Grimes, A.M., Hauth, A. and Andrews, C.J. (2008) Impact of Extended-Spectrum Antibiotic Prophylaxis of Cesarean Incidence of Post Surgical Wound Infection. American Journal of Obstetrics and Gynecology, No. 199, 303-306. http://www.Ajog.org

[19] Gong, S.P., Guo, H.X., Zhou, H.Z., Chen, L. and Yu, Y.H. (2012) Morbidity and Risk Factors for Surgical Site Infection Following Cesarean Section in Guangdong Province, China. The Obstetrics and Gynecology Research, 38, 509-515. https://doi.org/10.1111/j.1447-0756.2011.01746.x

[20] Wloch, O., Wilson, J., Lamagni, T., Harrington, P., Charlett, A. and Scheridan, E. (2012) Risk Factors for Surgical Site Infection Following Caesarean Section in England: Results from a Multicenter Cohort Study. International Journal of Obstetrics and Gynecology, 119, 1324-1333.

[21] Conroy, K., Yu, Y.H., Courtney, A., Lee, H.J. and Norwitz, E.R. (2012) Infectious Morbidity After-Cesarean Delivery 10 Strategies to Reduce Risk. Obstetric and Gynecology Reviews, 5, 69-77. 